Wilfrid Laurier University

Scholars Commons @ Laurier

Kinesiology and Physical Education Faculty

Publications

Kinesiology and Physical Education

$9-2009$

\title{
Perceptions of Cohesion by Youth Sport Participants
}

Mark Eys

Wilfrid Laurier University, meys@wlu.ca

Todd Lougheed

University of Windsor

Steven R. Bray

McMaster University

Albert V. Carron

University of Western Ontario

Follow this and additional works at: https://scholars.wlu.ca/kppe_faculty

\section{Recommended Citation}

Eys, Mark; Lougheed, Todd; Bray, Steven R.; and Carron, Albert V., "Perceptions of Cohesion by Youth Sport Participants" (2009). Kinesiology and Physical Education Faculty Publications. 7.

https://scholars.wlu.ca/kppe_faculty/7

This Article is brought to you for free and open access by the Kinesiology and Physical Education at Scholars Commons @ Laurier. It has been accepted for inclusion in Kinesiology and Physical Education Faculty Publications by an authorized administrator of Scholars Commons @ Laurier. For more information, please contact scholarscommons@wlu.ca. 


\title{
Perceptions of Cohesion by Youth Sport Participants
}

\author{
Mark A. Eys \\ Wilfrid Laurier University \\ Todd M. Loughead \\ University of Windsor \\ Steven R. Bray \\ McMaster University \\ Albert V. Carron \\ University of Western Ontario
}

\begin{abstract}
Cohesion is an important small group variable within sport. However, the conceptualization and examination of cohesion have predominately been oriented toward adult populations. The purpose of the current study was to garner an understanding of what cohesion means to youth sport participants. Fifty-six team sport athletes $\left(\mathrm{M}_{\text {age }}=15.63\right.$ \pm 1.01 years) from two secondary schools took part in focus groups designed to understand participants' perceptions of (a) the definition of cohesion and indicators of cohesive and noncohesive groups and (b) methods used to attempt to develop cohesion in their groups. Overall, the responses to part (a) yielded 10 categories reflecting a group's task cohesion and 7 categories reflecting a group's social cohesion. Finally, participants highlighted eight general methods through which their groups developed cohesion. Results are discussed in relation to a current conceptualization of cohesion and affiliation considerations within a youth sport environment.
\end{abstract}

"Without even exchanging a glance with Jardine, Jackson charges over the top, sets a screen, then rolls to the basket to receive one of Jardine's pinpoint passes for a layup. It's a chemistry two [high school basketball] seniors can develop when they've been playing together almost daily for four years and spend almost every waking moment together." (Mannix, 2007, p. 33)

This quote highlights a situation that is common in youth sport; a close affiliation between teammates both on and off the field of play. In fact, affiliation with other group members is a salient participation motive for youth engaging in sport (Weiss \& Petlichkoff, 1989). However, it is also likely that not all group members

Eys is with the Depts of Kinesiology/Physical Education and Psychology, Wilfrid Laurier University, Waterloo, Ontario, Canada N2L 3C5. Loughead is with the Dept. of Kinesiology, University of Windsor, Windsor, Ontario, Canada. Bray is with the Dept. of Kinesiology, McMaster University, Hamilton, Ontario, Canada. Carron is with the School of Kinesiology, University of Western Ontario, London, Ontario, Canada. 
consider themselves close with other members of their team. As a result, there are a number of levels of affiliation that exist within teams that make the analysis of group dynamics complex. The present study discusses these levels of affiliation and specifically focuses on youths' perceptions of what it means to be a member of a cohesive physical activity/sport group.

Smith (2007) noted that an individual's connection to his/her peer group and opportunities for friendships are factors that consistently have been discussed with regard to the concept of affiliation in sport. Smith summarized evidence supporting the importance of peer relationships in sport noting that (a) youth perceive competence in sport to be an important factor determining the quality of their interaction with peers, (b) sport acts as a "social currency" (p. 48) allowing for greater peer acceptance and opportunities to develop friendships, and (c) these relationships, in turn, influence the motivation to participate in sport and other self-perceptions (e.g., affect).

Smith (2007) also pointed out that the majority of research concerning peer relationships (e.g., Holt, Black, Tamminen, Fox, \& Mandigo, 2007; Smith, 2007; Wisdom \& Smith, 2007) has focused on individual perceptions (e.g., friendships, peer acceptance) in sport despite the presence of multiple levels of affiliation. Smith's observation has been echoed by Rubin, Bukowski, and Parker (2006); they noted that multiple levels of affiliation are present in the social environment of children and adolescents. These include, in increasing order of complexity: (a) the individual, (b) interactions, (c) relationships, and (d) groups. Considering affiliation from an individual perspective, Rubin et al. pointed out that every person brings relatively stable qualities to social exchanges that can include a range of social skills and cognitions. The next level of complexity, interactions, is marked by some sort of jointly undertaken social exchange between two individuals.

The third level, relationships, differs from interactions in that the former encompass "meanings, expectations, and emotions that derive from a succession of interactions [italics added] between two individuals known to each other" (Rubin et al., 2006, p. 577). It is at this level that concepts such as friendship (i.e., positive dyadic relationships that are reciprocal, affective, and voluntary) and enmities (i.e., dyads whose members have a mutual dislike for each other) are considered to be housed.

Finally, the group is considered to be the most complex level in the Rubin et al. framework. The constitutive definition of a group differs widely within the literature (e.g., Bass, 1960; Fiedler, 1967; Newcomb, 1951; Sherif \& Sherif, 1956). As one example, Rubin et al. (2006) defined a group as a collection of interacting individuals who have some degree of reciprocal influence over one another. As a further example, Carron, Hausenblas, and Eys (2005) differentiated between a 'collection of individuals' and a 'group' by defining the latter more specifically as:

a collection of two or more individuals who possess a common identity, have common goals and objectives, share a common fate, exhibit structured patterns of interaction and modes of communication, hold common perceptions about group structure, are personally instrumentally interdependent, reciprocate interpersonal attraction, and consider themselves to be a group. (p. 13) 
While it is possible to greatly expand upon each of the levels identified by Rubin et al. (i.e., interactions, relationships, and groups), two specific issues should be further explored. First, events that occur at one level of this framework are greatly influenced by the events that occur at all other levels (Rubin et al., 2006). For example, a group is no doubt influenced by the type, frequency, and quality of the interactions and relationships among its members. Consequently, relationship and interaction concepts such as friendship, peer acceptance, and dyadic communication can become blurred with more complex group concepts, properties, and/or processes.

One such group property is cohesion. Cohesion has been defined as "a dynamic process that is reflected in the tendency of a group to stick together and remain united in the pursuit of its instrumental objectives and/or for the satisfaction of member affective needs" (Carron, Brawley, \& Widmeyer, 1998, p. 213). The conceptual model of cohesion proposed by Carron, Widmeyer, and Brawley (1985) was derived from the constitutive definition outlined above, prior literature, and qualitative studies (e.g., focus groups) with intercollegiate and club athletes approximately 18-35 years of age. This conceptualization highlights that cohesion encompasses both task- and social-oriented aspects within the group and that perceptions are related to the degree of unity the group possesses and the manner in which personal objectives are met by group involvement (Carron, Brawley, \& Widmeyer, 2002). Consequently, four dimensions constitute the conceptual model proposed by Carron et al. (1985) including Group Integration-Task (i.e., perceptions of the degree of unity the group possesses surrounding task aspects), Group Integration-Social (i.e., perceptions of the degree of unity the group possesses regarding social aspects), Individual Attractions to the GroupTask (i.e., perceptions of personal involvement in task aspects of the group), and Individual Attractions to the Group-Social (i.e., perceptions of personal involvement in social aspects of the group).

As one indication of its influence, Lott and Lott (1965) described cohesion as the most important small group variable. Overall, a vast number of studies in sport and physical activity contexts have provided support for this contention. For instance in sport, cohesion has been shown to be positively related to team success (e.g., Carron, Colman, Wheeler, \& Stevens, 2002), collective efficacy (e.g., Spink, 1990), and various aspects of effective role involvement (e.g., Eys \& Carron, 2001). As another example, in physical activity groups, cohesion has been shown to be positively related to adherence (Spink \& Carron, 1994) as well as improved attitudes toward exercise (Estabrooks \& Carron, 1999).

However, with a few exceptions (e.g., Granito \& Rainey, 1988; Gruber \& Gray, 1982; Schutz, Eom, Smoll, \& Smith, 1994), the examination of cohesion and discussion of its conceptual issues have predominately been oriented toward adult populations. This leads to the second major issue with regard to our understanding of the levels of affiliation presented by Rubin et al. (2006). That is, it would be inappropriate to assume that conceptual models within each level that were developed for a specific age group are applicable to other age groups. For example, at the relationship level, Rubin et al. noted that the concept of friendship changes (i.e., becomes more abstract) as children grow older. Consequently, at the group level, it is reasonable to propose that perceptions of what cohesion means may also be different for youths than for older (and younger) individuals. Dion 
(2000) suggested this very point, outlining that perceptions of cohesion are likely to differ between groups that are dissimilar in nature (e.g., in goal orientation, types of tasks undertaken, etc.). In addition to the general suggestion that dissimilar groups may perceive the concept of cohesion differently, there is some evidence to suggest that Carron et al.'s (1985) underlying conceptual model of cohesion in sport may not be relevant to a younger population. Specifically, Schutz et al. (1994) examined the factor structure of the Group Environment Questionnaire (i.e., the operationalization of cohesion developed by Carron et al., 1985) with individuals ranging in age from 13 to 19 years. They found that the hypothesized factor structure of the questionnaire (based on the dimensions of cohesion outlined previously) was not supported with their sample. While there are a multitude of potential reasons why this result was found (e.g., item relevancy or wording), it is not unreasonable to suggest that one reason is that the conceptual model developed with and for adults might not be relevant to a younger population.

Therefore, given (a) the importance of insuring conceptual clarity regarding the multiple levels of affiliation, (b) the significant role cohesion has played in adult sport and physical activity groups, and (c) our lack of understanding of youth perceptions of cohesion, the purpose of the current study was to garner an understanding of what cohesion means to youth sport participants. A secondary purpose was to examine participants' perceptions of how cohesion develops in their groups. A qualitative methodology was used to achieve these purposes.

\section{Method}

\section{Participants}

The participants were 56 youth team sport participants $\left(n_{\text {males }}=30, n_{\text {females }}=26\right)$ from two secondary (high) schools in the province of Ontario (Canada). The relatively equal balance of males and females was deliberate to insure that the results were not gender-specific. One high school was located in the northeastern part of Ontario while the other was located in the Southwestern part of the province. The participants engaged in a variety of interactive sports. These included rugby, basketball, hockey, volleyball, soccer, doubles badminton, doubles tennis, field hockey, and football at a variety of competitive levels. A heterogeneous sample of sports was sampled to insure that the results were not sport-specific. The mean age of the participants was $15.63 \pm 1.01$ years and the ages ranged from 14 to 17 .

\section{Design and Procedure}

Ethical approval was obtained to conduct the study and permission was subsequently granted from the principals of the secondary schools to solicit volunteers to participate. Volunteers were given verbal information on the purpose of the investigation and asked to sign a consent form and obtain permission from a parent/guardian to participate. Once consent was obtained from both the participants and their parents/guardians, each individual was placed in one of seven focus groups (four focus groups at the northeastern Ontario high school and three focus groups at the Southwestern Ontario high school) with the intention of creating heterogeneous groups in terms of gender and sport type. The focus groups 
were conducted during school time at a location within the school convenient to all parties (i.e., the participants, school administrators, and researchers).

A focus group methodology was chosen for two reasons. First, this approach replicated earlier work on cohesion perceptions with young adults by Carron et al. (1985). Second, Thomas, Nelson, and Silverman (2005) suggested that the information obtained from focus groups can be richer and more in-depth than that obtained on an individual basis from the same number of people. One advantage, for example, is that individuals participating in a focus group can expand on answers provided by other group members. A single category design (Krueger \& Casey, 2000) was used with the ultimate goal of reaching theoretical saturation regarding perceptions of cohesion. Each focus group consisted of the participants and a moderator who posed questions and probed responses. An interview guide was used based on suggestions by Krueger and Casey (2000) and Patton (1990). This interview guide ${ }^{1}$ contained (a) introductory questions (i.e., questions to encourage participation and conversation between the participants), (b) transition questions (i.e., questions designed to move the discussion toward the critical subject), (c) four key questions (i.e., questions designed specifically for the purposes of the current study), and (d) an ending question (i.e., designed to close discussion but also to allow any further thoughts/concerns to emerge). The four key questions (see Appendix) were concerned with understanding participants' perceptions of (a) the definition of cohesion and indicators of cohesive and noncohesive groups (questions one to three) and (b) methods used to attempt to develop cohesion in their teams or groups (question four).

In addition to the above, the moderators were trained to use probing questions to allow participants to expand upon responses (Krueger \& Casey, 2000). The goal of the research team was to have each session last approximately 45 minutes. However, the duration of the seven focus groups ranged from 40 to 75 minutes.

\section{Data Analysis}

Each focus group was audiotaped and responses were transcribed verbatim. A combination of inductive and deductive approaches to the categorization of responses was used. This type of approach has been considered reasonable and realistic by qualitative researchers (e.g., Munroe-Chandler, Hall, Fishburne, \& Strachan, 2007; Patton, 2002; Vazou, Ntoumanis, \& Duda, 2005) because, as Munroe-Chandler et al. stated, " no researcher designs a study without some initial hypotheses based on previous research and theory" (p. 106).

In the current study, the categories that were created deductively were based heavily on previous research in a group environment. Specifically, the distinction between task and social aspects of the group's environment has been supported by research in organizational (e.g., Zaccaro \& Lowe, 1988) and sport psychology (e.g., Carron, Widmeyer, \& Brawley, 1985). Further, as Dion (2000) stated "The task-social distinction has . . . been proposed as being a primary dimension of cohesion that applies to most, if not all, groups" (p. 21). Consequently, this tasksocial distinction was used as the first level of categorization in the analysis of the present results.

The subsequent categories were created in an inductive fashion through the analysis of data. The process by which this occurred followed suggestions by 
Côté, Salmela, Baria, and Russell (1993). Specifically, the responses of participants were first subdivided into meaning units. Meaning units are phrases/words that represent a single idea (Tesch, 1990).

Overall, there were 195 meaning units related to the participants' conceptualization of cohesion and 78 related to methods to enhance cohesion. Each meaning unit was initially assigned to a task or social category. The next stage involved grouping meaning units representing a similar theme to form subcategories. This was completed by the first two authors independently and the initial assessment of consensus between them was $83.9 \%$ for the task category and $88.5 \%$ for the social category. The categorization of meaning units that were not initially agreed upon were further discussed until consensus was achieved. Thus, 100\% agreement was achieved at the end of the analysis phase.

The trustworthiness of the findings was enhanced by considering issues of validity in qualitative research proposed by Maxwell (2002). Specifically, the descriptive validity of the study was enhanced by ensuring the accurate collection of focus group discussions through audiotape and having the content on these tapes transcribed verbatim by a trained graduate research assistant. Theoretical validity was supported by relating/comparing the obtained data to an existing conceptual model of cohesion and striving to account for all meaning units within the dataset. Finally, an attempt to enhance the generalizability of the findings was made by the inclusion of participants from a broad spectrum of sports, both genders, and the full age range of interest.

\section{Results}

\section{Purpose 1: Meaning of Cohesion to Youth Sport Participants}

An overview of the findings is presented in Figure 1. As was previously noted, 195 meaning units were obtained from the focus groups and the number of meaning units for each category are presented in parentheses. It is important to note, however, that the frequency with which a particular category was discussed in the focus groups is not necessarily an indication of importance (Krane, Anderson, \& Strean, 1997). The subsequent sections contain a discussion of the subcategories housed under task cohesion and social cohesion. Direct quotations from participants are provided to further illustrate their meaning. It should also be noted that some editorial license has been taken to improve the clarity of the quotations (e.g., removing/editing of habitual usage of "like" and other slang such as "kinda"); extreme care was taken in order not to alter the meaning. Finally, a relatively balanced presentation of positive and negative comments is provided. With few exceptions, the individual categories were derived through a combination of both types of comments. In relation to negative comments, it could be argued that these are perceptions of what is not cohesion rather than cohesion itself. However, we operated under the assumption that certain characteristics of cohesion or of a cohesive team may not become salient until the group or its members violate the behavioral representations of these characteristics (i.e., not being unselfish). This suggestion has been made with regard to the nature of other concepts such as group norms (Carron et al., 2005). 


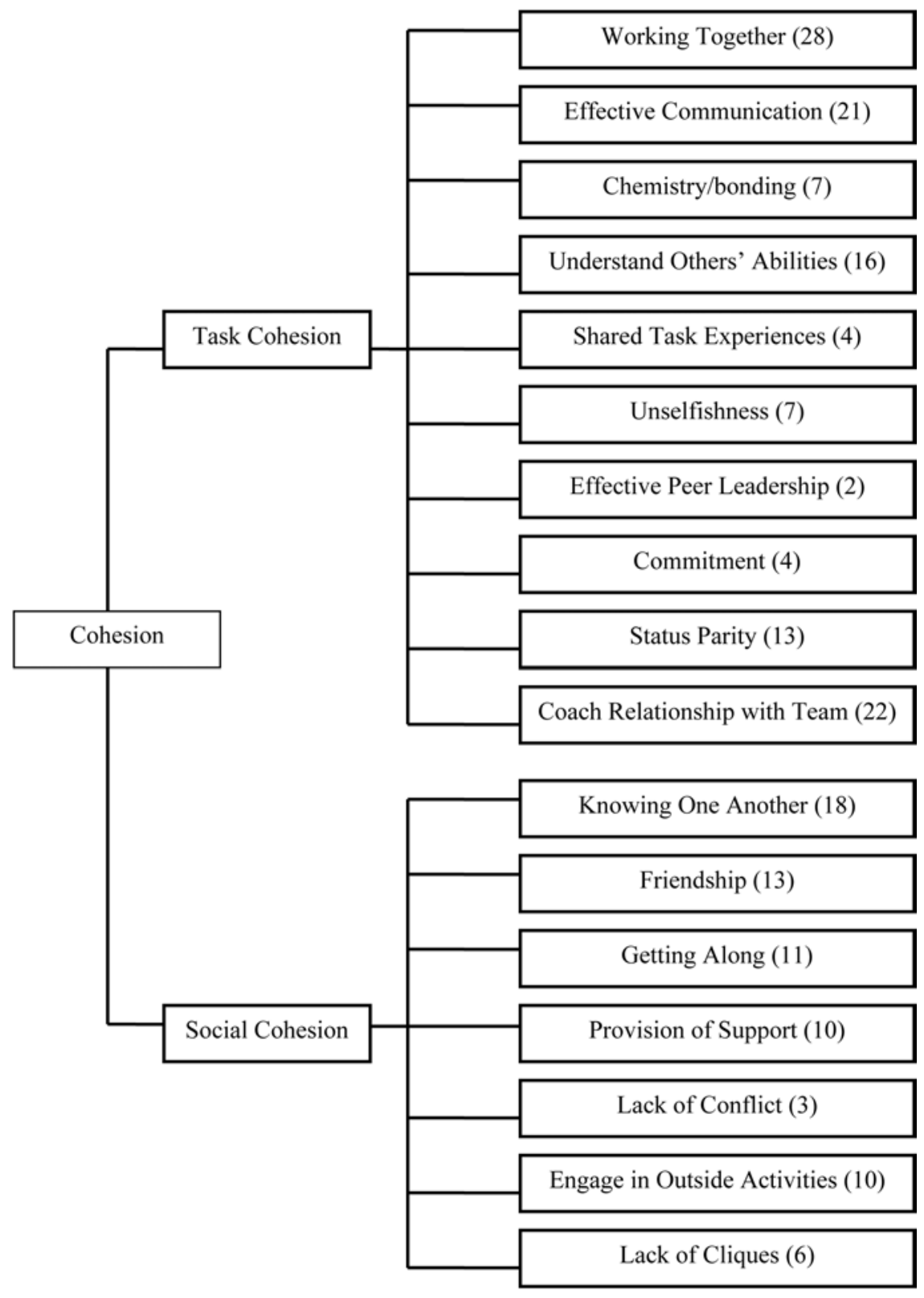

Figure 1 - A conceptual framework for perceptions of cohesion by youth participants (number of meaning units in parentheses). 
Task cohesion. As a whole, the responses to questions one to three yielded 124 meaning units that resulted in 10 categories reflecting a group's task cohesion (see Figure 1). A number of participants discussed the concept of 'Working Together' as an indicator of cohesion. For example, a male high school soccer player commented "I think it's like a machine, it just works well together, everything slides into place." Another indicator of task cohesion was 'Effective Communication' among players. Commenting on a cohesive team he once participated on, a rugby player noted:

It was necessary to make some constructive comments about the mistakes your friends or buddies have done ... it was not a bad thing to comment on their mistakes and to do this and do that so we can get a try.

'Chemistry/bonding' was another category—one that reflected more abstract perceptions of the group coming together as a whole. This was illustrated by a hockey player who stated:

We've been considered not one of the more skilled teams in the league, but yet since we're with each other five times a week . . . we're always bonding together in the dressing room, we're considered like brothers and like a family and everything.

The category 'Understanding Others' Abilities' reflected meaning units describing knowledge of what others were capable of achieving. For example, cohesion was referred to as "knowing each others' skills and their strengths and weaknesses, which can really help the overall team."

Although labeled in the positive, the category 'Unselfishness' was typically derived from responses to the question concerning what goes on in a noncohesive group (i.e., individuals are selfish). The quote "Whenever there is one guy on the team that will try to do everything, as opposed to using the teammates" is an example of one response.

The categories 'Effective Peer Leadership' (e.g., "Last season we had a captain who was kind of over dominating in he was too vocal . . . he yelled at us after every play") and 'Commitment' (e.g., "commitment was low, and practices ended up being just an hour long as opposed to two hours and just nothing really took off') were derived from responses indicating both positive and negative reflections of a group's cohesion (although only negative examples are used herein).

The final two categories reflected the structural aspects of the group. One, 'Status Parity', categorized responses indicating the need for status differences to be minimized on a number of characteristics such as ability (e.g., "the good players will try to go at their level, rather than bringing along the rest of the team") and age (e.g., "I found that the older ones stick together, and the younger ones stick together, and the older ones don't pass to the younger ones"). The other category, 'Coach Relationship with Team', contained responses highlighting this relationship as an important indicator of group cohesion (e.g., "Your coach [coaches] in a positive way, treats everyone fairly").

Social Cohesion. The responses to questions one to three yielded 71 meaning units that resulted in seven categories that were felt to reflect a group's social 
cohesion (see Figure 1 again). Specifically, these meaning units reflected relational ideas such as 'Knowing One Another' (e.g., "if you don't really know very many people on your team and you're losing a lot of games it'll just draw everybody apart"), 'Friendship' (e.g., "If you are friends, it means you have played together before, you guys might already have cohesion), 'Getting Along' (e.g., "I just think that a team is truly cohesive if they can lose a game and still laugh about it afterwards and still have a good time"), 'Lack of Conflict' (e.g., "a lot of infighting and conflict ... it usually gets worse and worse"), and 'Lack of Cliques' (e.g., "Our girls' rugby team this year is pretty cliquey. They will leave people out").

The final two categories reflected typical behaviors of cohesive groups that included 'Provision of Support' (e.g., "In sports like basketball and soccer it's really important to be able to support each other") and 'Engage in Outside Activities' (e.g., "Going to tournaments, going out for dinner at the same restaurant, when we all stay in a hotel").

\section{Purpose 2: The Development of Cohesion in Youth Sport and Physical Activity Groups}

The categories in which meaning units were placed regarding perceptions of how cohesion had been developed in youth sport and physical activity groups are presented in Figure 2. A total of 78 meaning units were obtained from the focus

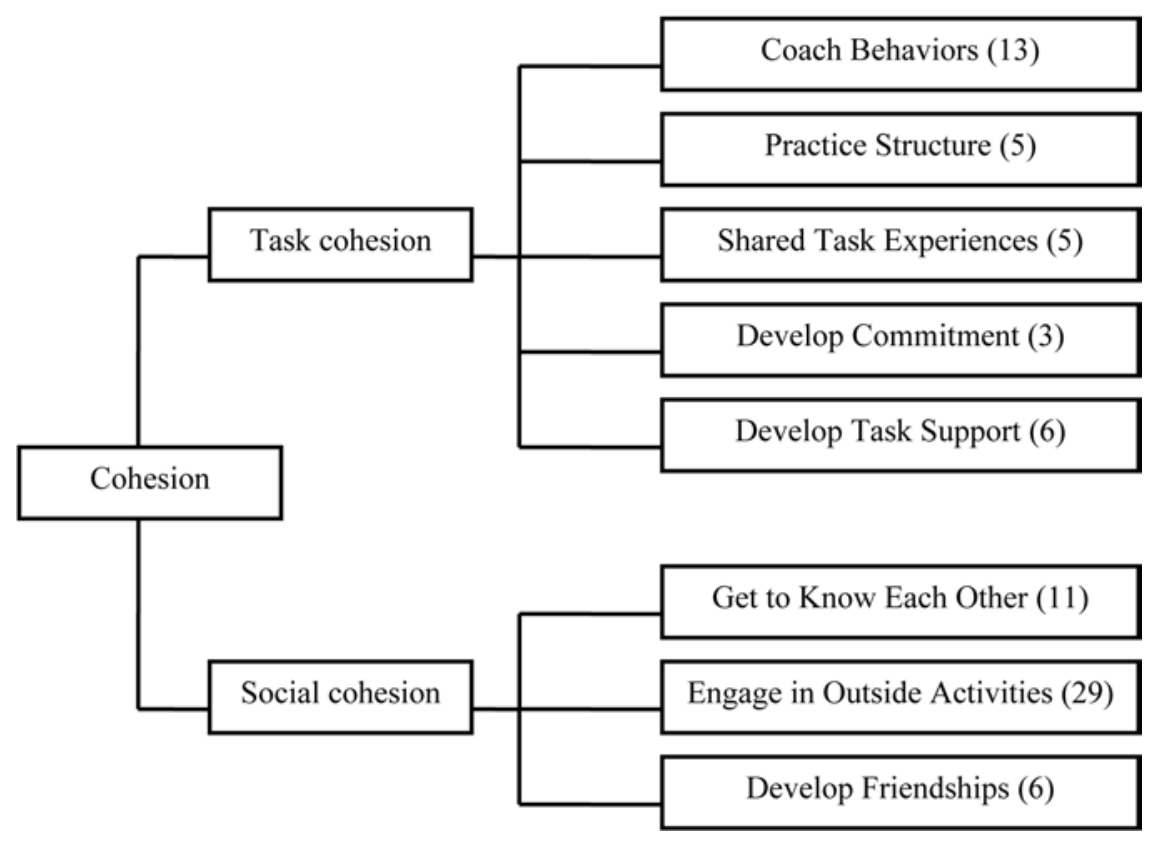

Figure 2 - Perceptions of how cohesion is developed in youth sport and physical activity groups (number of meaning units in parentheses). 
groups with regard to this purpose and the number of meaning units for each category is presented in parentheses.

Task Cohesion. The participants' responses (32 meaning units) were represented by five categories related to the development of task cohesion. Specifically, these included behaviors initiated by the coach (i.e., 'Coach Behaviors') highlighted by quotes such as "Treating everyone fairly", engaging in "one-on-one meetings", and "I think it depends a lot on the coach. If you get along with the coach, you will have a good year." In addition, 'Shared Task Experiences' (e.g., "If you know we're going to run for this amount of time then you're kind of more cohesive ... you're doing it together so it forces you to try and push yourself') and the development of an effective 'Practice Structure' (e.g., "Not just doing boring drills as much, and being in smaller teams") are likely under the control of the coach and highlight the need to consider the group's task environment.

The final two categories suggest the need to 'Develop Commitment' (e.g., "I think commitment is a huge part of it, because if not all of . . the players on the team are as committed, you'll see them not showing for practice [and] maybe not putting in their best) and 'Develop Task Support' (e.g., "When [the other players] are trying really hard just cheer them on and say that they're doing a good job, good effort")

Social Cohesion. Participants' responses (46 meaning units) were represented by three categories related to the development of social cohesion. Similar to their views about what represents cohesion in their physical activity environment, participants highlighted the need to 'Get to Know Each Other' (e.g., "The more time your group spends together, the more the group gets to know each other, the more everyone will start having fun together"), 'Engage in Outside Activities' (e.g., "We went out for supper a couple of times, we went paint balling, as silly as that sounds, and then just little activities and stuff and it really helps"), and 'Develop Friendships' (e.g., "I find there's a lot more cohesion when you have a big group of friends on the team, because you're just more comfortable with each other... that's just something that really made the group cohesive").

\section{Discussion}

The purpose of the current study was to examine the meaning of cohesion for youth sport participants and their perceptions of how it develops in their teams and physical activity groups. Five issues arose that warrant further discussion.

First, support was shown for the decision to use a deductive strategy and group responses into either task- or social-related categories. As was pointed out above, the decision was based on theoretical perspectives advanced in organizational and sport psychology (e.g., Carron et al., 1985; Zaccaro \& Lowe, 1988) as well as Dion's (2000) overview of the cohesion literature. Based on the results of the current study (i.e., initial placement of meaning units into these categories), this appears to be a reasonable distinction to use with youth sport and physical activity groups (and likely a robust distinction to make across age groups). Specifically, participants referred to both task and social aspects of cohesion and there 
were no extraneous meaning units or expressions that did not fall under one of these two categories.

A second issue, one related to the above point, is associated with the question of whether the task subcategory, Coach Relationship with Team, might be considered a separate and primary dimension of cohesion. Dion (2000) pointed out that some theoreticians (e.g., Bliese \& Halverson, 1996) argue for a distinction between horizontal and vertical cohesion, which takes into account the direction of cohesion as opposed to the functions it serves (i.e., task and social aspects). Thus, horizontal cohesion refers to cohesion experienced within the group whereas vertical cohesion reflects relations between leaders and followers. As Dion noted, "Vertical cohesion refers to subordinates' perceptions of their leaders' competence and considerateness" (p. 12).

The coach's effect on the group and its cohesiveness were obviously relevant to participants in the current study and therefore it is worthwhile to discuss further. The concept of 'vertical cohesion' as defined by Dion (2000; i.e., perceptions of leader competence and considerateness) is certainly attractive to consider in the context of sport and, in fact, has been examined under various other labels. For example, with regard to coach competence, Bray and colleagues (Bray, Gyurcsik, Martin Ginis, \& Culos-Reed, 2004; Bray \& Shields, 2007) have recently introduced the concept of proxy efficacy or "one's confidence in the skills and abilities of a third party or parties to function effectively on one's behalf' (Bray et al., p. 426). The coach was utilized by Bray and Shields as an example of a proxy agent in a sport environment.

In addition, the consideration of coaches and the more affective aspects of the coach-athlete relationship have been examined in a series of studies by Jowett and colleagues (e.g., Jowett \& Chaundy, 2004; Jowett \& Ntoumanis, 2004). As Jowett (2007) stated "A coach is viewed as central in turning a collection of individuals into a group (i.e., a team unit) by building and managing the various dyadic coachathlete relationships" (pp. 63-64). Interestingly, Jowett and Chaundy (2004) found a positive relationship between perceptions of the coach-athlete relationship and cohesion in university age athletes. Essentially, their study demonstrated a positive relationship between vertical and horizontal cohesion in sport which supports previous research in other contexts (e.g., military units; Bliese \& Halverson, 1996).

Fundamentally, the question is whether the leader (coach) is an integral member of the team or one of the many principals (albeit a preeminent one) who directs and interacts with the team to facilitate its achievement of desired objectives. It is our contention that although we have included coach issues within the general task results, in sport it is necessary to consider cohesion among peers (i.e., horizontal cohesion) as something distinct from (but related to) coach-athlete issues.

Ultimately, the previous discussion raises a third major issue related to one of the objectives of the current study, which is whether the results have provided conceptual clarity to the construct of cohesion in and among the variety of other affiliation variables (e.g., friendship, peer acceptance, etc.). An examination of the subcategories described in the results and presented in Figure 1 contributes to the suggestion that cohesion is considered an abstract concept to youths and one that seems to be represented by a number of synonyms (e.g., "Chemistry") as well as 
potential antecedents (e.g., "Friendship", "Participation in Outside Activities") and consequences (e.g., "Effective Communication", "Lack of Conflict"). This supports Rubin et al.'s (2006) recognition of the inherent links among various levels of affiliation (i.e., interactions, relationships, and groups) and complexity of group level concepts. It is also compatible with operational measures of cohesion with other populations (e.g., Group Environment Questionnaire; Carron et al., 1985). For example, an examination of items in the Group Environment Questionnaire (i.e., as indicated above, a multidimensional sport cohesion questionnaire initially developed with and for athletes over the age of 18) demonstrates congruency with many of the perceptions uncovered in the current study such as Friendship (e.g., "Some of my best friends are on this team") and Engaging in Outside Activities (e.g., "Members of our team . . . stick together outside of practices and games"). Overall, similar to adult populations examined, it appears that affective, cognitive, and behavioral representations of various interactions and relationships amalgamate to form the more abstract concept of cohesion.

A fourth issue is related to a major premise of the current study; that perceptions of cohesion will likely be different across the developmental life span. That is, what can be said about the uniqueness of the information reported in the current study relative to previous research? First, without further research, it is difficult to state with any certainty what aspects of cohesion are most salient for this population. As was mentioned in the results section, it is not possible to confer importance to certain ideas simply based on the frequency with which they were discussed. The development of an operational measure of cohesion for youths would greatly assist in determining the salience of these categories.

Regardless, another point to consider is that youths seem to view cohesion as multidimensional and, albeit constrained within the deductive analysis method, containing task and social elements. In and of itself, this is not distinguishable from an accepted conceptualization of cohesion in sport and physical activity developed by Carron and colleagues (1985). However, Carron et al.'s conceptualization also included a further distinction based on the focus of perception; those of (a) individual attractions to the group and (b) group integration. This individual-group distinction was created based on previous theorizing that one reflection of cohesion is the attractiveness of the group to the individual (e.g., Gross \& Martin, 1952). With regard to the current study, a post hoc analysis of information obtained through the focus groups did not yield meaning units referring to the individual attractions to the group concept. In addition, the vast majority of comments contained references to "we" and "us" (i.e., manifesting the group integration concept). One possibility to explain this observation is that youths do not necessarily share the view of some social psychologists that individual attractions to social and task aspects of the group are representative of the cohesion construct. However, another possibility is that the questions, probes, and prompts in the current study did not effectively examine this aspect of cohesion or allow for the participants to comment on it. Consequently, it would be unwise at this point to discount this perspective for this population until future research has had an opportunity to explore this issue further.

A final issue pertains to the perceptions of participants pertaining to how cohesion develops in their sport teams. As Figure 2 demonstrates, and probably not that surprising, the ideas behind the development of cohesion follow closely 
to the dimensions outlined in Figure 1. However, it is again worthwhile to highlight the interplay of the various levels of affiliation denoted by Rubin et al. (2006), which is particularly relevant for the categories of activities housed under social cohesion. These activities range from what could be construed as the initiation of simple interactions (i.e., getting to know each other), to the creation and nurturing of dyadic relationships (i.e., developing friendships), and finally to promoting the larger cohesive group (i.e., engaging in outside activities).

From an applied perspective, it should also be pointed out that the participants' responses to how individuals (e.g., coaches) have developed cohesion in their groups represents a very narrow perspective of the many avenues through which this group property can be improved. For example, in addition to nurturing opportunities to interact and communicate socially, suggested team building protocols with the direct or indirect purpose of enhancing cohesion (e.g., Spink \& Carron, 1992) include developing the group's sense of distinctiveness, it's structure (e.g., highlighting individual roles and positions), and member norms (i.e., behaviors expected from all teammates). As a further example of a method relevant to the development of cohesion, other interventions seek to create greater opportunities for teammates to openly and constructively discuss a team's task and social issues (Dunn \& Holt, 2004). The overall point is that there are a number of avenues to pursue the development of group cohesion to which the participants in the current study did not refer; this is not a statement on the quality of their responses but rather their exposure to methods devoted to developing group cohesion.

In sum, youth sport participants view cohesion as encompassing a number of concepts that link a variety of levels of affiliation and speak to the complexity of the issue. Given the important role cohesion seems to play in sport and physical activity contexts in older populations including both performance (e.g., Carron, Colman, et al., 2002) and adherence (e.g., Spink \& Carron, 1994), a greater conceptual understanding of this construct with a youth population will likely serve to prompt the development of a useful measure, spur greater research interest in the area, and foster increased enjoyment and participation in physical activity through effective, evidence-based methods to enhance group functioning.

\section{Acknowledgments}

The authors would like to thank the Social Sciences and Humanities Research Council of Canada (410-2005-0820) for its support of this project. A copy of the interview guide can be obtained by contacting the lead author.

\section{References}

Bass, B.M. (1960). Leadership, psychology, and organizational behavior. New York: Harper.

Bliese, P.D., \& Halverson, R.R. (1996). Individual and nomothetic models of job stress: An examination of work hours, cohesion, and well-being. Journal of Applied Social Psychology, 26, 1171-1189.

Bray, S.R., Gyurcsik, N.C., Martin Ginis, K.A., \& Culos-Reed, S.N. (2004). The Proxy Efficacy Exercise Questionnaire: Development of an instrument to assess female exercisers' proxy efficacy beliefs in structured group exercise classes. Journal of Sport \& Exercise Psychology, 26, 442-456. 
Bray, S.R., \& Shields, C.A. (2007). Proxy efficacy in physical activity. In M. Beauchamp \& M. Eys (Eds.), Group dynamics advances in sport and exercise psychology: Contemporary themes (pp. 79-95). Oxford: Routledge.

Carron, A.V., Brawley, L.R., \& Widmeyer, W.N. (1998). The measurement of cohesiveness in sport groups. In J.L. Duda (Ed.), Advances in sport and exercise psychology measurement (pp. 213-226). Morgantown, WV: Fitness Information Technology.

Carron, A.V., Brawley, L.R., \& Widmeyer, W.N. (2002). The Group Environment Questionnaire test manual. Morgantown, WV: Fitness Information Technology.

Carron, A.V., Colman, M.M., Wheeler, J., \& Stevens, D. (2002). Cohesion and performance in sport: A meta-analysis. Journal of Sport \& Exercise Psychology, 24, 168-188.

Carron, A.V., Hausenblas, H., \& Eys, M.A. (2005). Group dynamics in sport (3rd ed.). Champaign, IL: Human Kinetics.

Carron, A.V., Widmeyer, W.N., \& Brawley, L.R. (1985). The development of an instrument to assess cohesion in sport teams: The Group Environment Questionnaire. Journal of Sport Psychology, 7, 244-266.

Côté, J., Salmela, J.H., Baria, A., \& Russell, S.J. (1993). Organizing and interpreting unstructured qualitative data. The Sport Psychologist, 7, 127-137.

Dion, K.L. (2000). Group cohesion: From "field of forces" to multidimensional construct. Group Dynamics. Theory, Research, and Practice, 4, 7-26.

Dunn, J.G.H., \& Holt, N.L. (2004). A qualitative investigation of a personal-disclosure mutual-sharing team building activity. The Sport Psychologist, 18, 363-380.

Estabrooks, P.A., \& Carron, A.V. (1999). The role of the group with elderly exercisers. Small Group Research, 30, 438-452.

Eys, M.A., \& Carron, A.V. (2001). Role ambiguity, task cohesion, and task self-efficacy. Small Group Research, 32, 356-373.

Fiedler, F.E. (1967). A theory of leadership effectiveness. New York: McGraw-Hill.

Granito, V.J., \& Rainey, D.W. (1988). Differences in cohesion between high school and college football teams and starters and nonstarters. Perceptual and Motor Skills, 66, 471-477.

Gross, N., \& Martin, W.E. (1952). On group cohesiveness. American Journal of Sociology, 57, 546-554.

Gruber, J.J., \& Gray, G.R. (1982). Responses to forces influencing cohesion as a function of player status and level of male varsity basketball competition. Research Quarterly for Exercise and Sport, 53, 27-36.

Holt, N., Black, D., Tamminen, K., Fox, K., \& Mandigo, J. (2007). Orders of social complexity and early adolescent females' peer experiences in sport. Proceedings of the Canadian Society for Psychomotor Learning and Sport Psychology, Windsor, Ontario, Canada, 38.

Jowett, S. (2007). Coach-athlete relationships ignite sense of groupness. In M. Beauchamp \& M. Eys (Eds.), Group dynamics advances in sport and exercise psychology: Contemporary themes (pp. 63-77). Oxford: Routledge.

Jowett, S., \& Chaundy, V. (2004). An investigation into the impact of coach leadership and coach-athlete relationship on group cohesion. Group Dynamics: Theory. Research and Practice, 8, 302-311.

Jowett, S., \& Ntoumanis, N. (2004). The Coach-Athlete Relationship Questionnaire (CART-Q): Development and initial validation. Scandinavian Journal of Medicine \& Science in Sports, 14, 245-257.

Krane, V., Anderson, M.B., \& Strean, W.B. (1997). Issues of qualitative research methods and presentation. Journal of Sport \& Exercise Psychology, 19, 213-218.

Krueger, R.A., \& Casey, M.A. (2000). Focus group: A practical guide for applied research. Thousand Oaks, CA: Sage.

Lott, A.J., \& Lott, B.E. (1965). Group cohesiveness as interpersonal attraction: A review of relationships with antecedent and consequent variables. Psychological Bulletin, 64, 259-309. 
Mannix, C. (2007). Joined at the hoop. Sports Illustrated, 106(1), 33.

Maxwell, J. (2002). Understanding and validity in qualitative research. In A.M. Huberman \& M.B. Miles (Eds.), The qualitative researcher's companion (pp. 37-64). Thousand Oaks, CA: Sage.

Munroe-Chandler, K.J., Hall, C.R., Fishburne, G.J., \& Strachan, L. (2007). Where, when, and why young athletes use imagery: An examination of developmental differences. Research Quarterly for Exercise and Sport, 78, 103-116.

Newcomb, T.M. (1951). Social psychological theory. In J.H. Rohrer \& M. Sherif (Eds.), Social psychology at the crossroads. New York: Harper.

Patton, M.Q. (1990). Qualitative evaluation and research methods (2nd ed.). Newbury Park, CA: Sage.

Patton, M.Q. (2002). Qualitative research and education methods (3rd ed.). Newbury Park, CA: Sage.

Rubin, K.H., Bukowski, W., \& Parker, J. (2006). Peer interactions, relationships, and groups. In N. Eisenberg (Ed.), Handbook of child psychology: Social, emotional, and personality development (6th ed., pp. 571-645). New York: Wiley.

Schutz, R.W., Eom, H.J., Smoll, F.L., \& Smith, R.E. (1994). Examination of the factorial validity of the Group Environment Questionnaire. Research Quarterly for Exercise and Sport, 65, 226-236.

Sherif, M., \& Sherif, C.W. (1956). An outline of social psychology (Rev. ed.). New York: Harper \& Row.

Smith, A.L. (2007). Youth peer relationships in sport. In S. Jowett \& D. Lavallee (Eds.), Social psychology in sport (pp. 41-54). Champaign, IL: Human Kinetics.

Spink, K.S. (1990). Group cohesion and collective efficacy of volleyball teams. Journal of Sport \& Exercise Psychology, 12, 301-311.

Spink, K.S., \& Carron, A.V. (1992). Group cohesion and adherence in exercise classes. Journal of Sport \& Exercise Psychology, 14, 78-86.

Spink, K.S., \& Carron, A.V. (1994). Group cohesion effects in exercise classes. Small Group Research, 25, 26-42.

Terry, P.C., Carron, A.V., Pink, M.J., Lane, A.M., Jones, G.J.W., \& Hall, M.P. (2000). Perceptions of group cohesion and mood in sport teams. Group Dynamics. Theory, Research, and Practice, 4, 244-253.

Tesch, R. (1990). Qualitative research analysis types and software tools. New York: Falmer.

Thomas, J.R., Nelson, J.K., \& Silverman, S.J. (2005). Research methods in physical activity (5th ed.). Champaign, IL: Human Kinetics.

Vazou, S., Ntoumanis, N., \& Duda, J.L. (2005). Peer motivational climate in youth sport: A qualitative inquiry. Psychology of Sport and Exercise, 6, 497-516.

Weiss, M.R., \& Petlichkoff, L.M. (1989). Children's motivation for participation in and withdrawal from sport: Identifying the missing links. Pediatric Exercise Science, 1, 195-211.

Wisdom, S.A., \& Smith, A.L. (2007). Peer relationship profile differences on moral reasoning in youth soccer. Journal of Sport \& Exercise Psychology, 29, S219.

Zaccaro, S.J., \& Lowe, C.A. (1988). Cohesiveness and performance on an additive task: Evidence for multidimensionality. The Journal of Social Psychology, 128, 547-558. 


\section{Appendix}

\section{Key questions:}

1. When a group forms, the individuals you mentioned before have to interact with each other and participate in the activities as a group. In relation to these physical activity groups, what does the term "cohesion" mean to you? Define cohesion?

2. Thinking back to your experiences on a team or physical activity group, what are some of the things you have observed that would lead you to believe that your team was very cohesive?

3. Now think back again to your experiences as a group member and tell me some of the things you have observed that would lead you to believe that your team or group was not very cohesive?

4. The prior questions tried to determine what you thought cohesive and noncohesive groups might look like. Please tell me some of the ways people could develop cohesion in a physical activity group or team or tell me some of the ways people have developed cohesion in your teams or groups. 